\title{
Estimation of Phosphorus Content in Archaeological Iron Objects by Means of Optical Metallography and Hardness Measurements
}

\author{
Ádám Thiele \\ Budapest University of Technology and Economics, Faculty of Mechanical \\ Engineering, Department of Materials Science and Engineering \\ Bertalan Lajos u. 7, Bdg. MT, H-1111 Budapest, Hungary, thiele@eik.bme.hu
}

\section{Jiří Hošek}

Institute of Archaeology of the ASCR, Prague, v.v.i., Letenská 4, 11801 Prague 1, Czech Republic, hosek@arup.cas.cz

\footnotetext{
Abstract: In order to facilitate everyday archaeometallographic research into archaeological and/or historical objects, a method employing results of metallographic examination and hardness measurements to estimate phosphorus content in iron artifacts is introduced in the paper. Furthermore, phosphorus contents encountered in phosphoric iron that was used deliberately as a special material (for pattern-welding etc.) are discussed here. Despite certain limitations, the proposed method can be used for the estimation of the phosphorus content of archaeological iron examined either currently or in the past.
}

Keywords: Phosphoric iron; archaeometallurgy; archaeometallography; Vickers hardness

\section{Introduction}

\subsection{Archaeological and Archaeometric Background}

Iron with enhanced phosphorus content is known in archaeometallurgy, as phosphoric iron, the term being used for iron containing more than $0.1 \mathrm{wt} \% \mathrm{P}$ [1]. It is commonly encountered in archaeological iron objects regardless of the dating and provenance. 
Phosphorus, a natural admixture coming from bog iron ore, gives specific properties to iron, and it is not surprising that this issue has become a subject of interest to many researchers. It is currently well-known, that certain types of phosphoric iron were highly valued in the past, particularly for the possibility to be distinguished with the naked eye (under certain conditions) from nonphosphoric iron and steel.

Phosphorus is an avoided element in modern steel industry. Its detrimental effects include various forms of embrittlement, which reduce the toughness and ductility of steel. Phosphorus, a ferrite-stabilizing element, can be created with up to the maximum of $2.8 \mathrm{wt} \%$ in ferrite, as the Fe-P dual phase diagram shows in Fig. 1 [2].

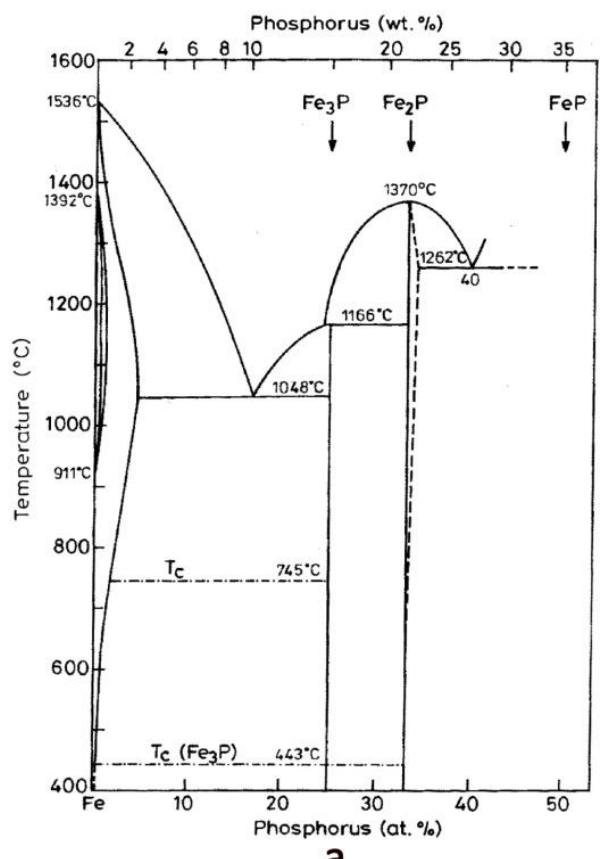

a

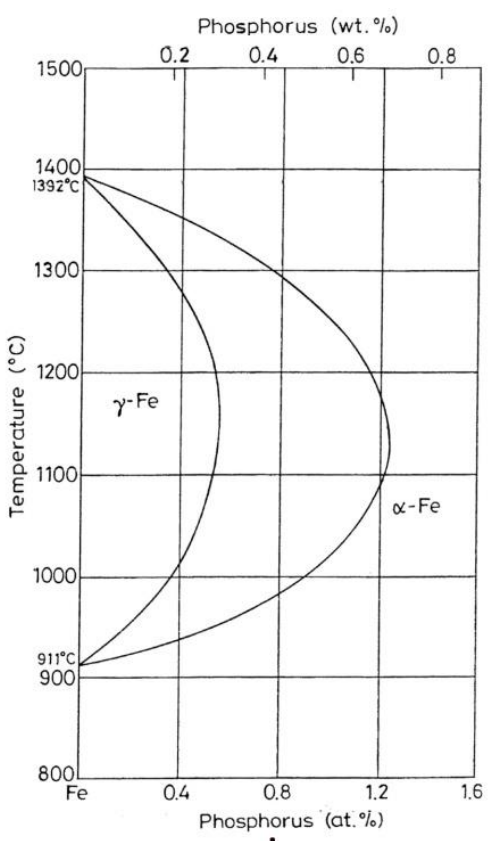

b

Figure 1

Fe-P dual phase diagram: a - phosphorus content up to $35 \mathrm{wt} \%, \mathrm{~b}-\alpha-\gamma$ the dual phase field

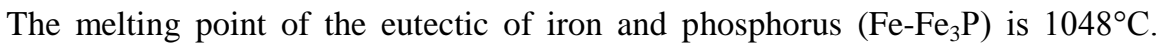
Above a certain temperature and phosphorus content $\left(1048^{\circ} \mathrm{C}\right.$ and $\left.2.8 \mathrm{wt} \% \mathrm{P}\right)$, a molten phase appears on the grain boundaries. Phosphoric iron of high phosphorus content is not forgeable, as the $\mathrm{Fe}-\mathrm{Fe}_{3} \mathrm{P}$ eutectic melts on the grain boundaries above the eutectic temperature. On the other hand, phosphoric iron of low phosphorus content cracks during cold-working due to its reduced ductility (cold shortness). If the amount of the $\mathrm{Fe}-\mathrm{Fe}_{3} \mathrm{P}$ eutectic is low, it is possible to forge weld the ferrite grains after the molten eutectic effuses just as molten slag does. 
Despite its poor mechanical properties, phosphoric iron was deliberately used in medieval metal-working for the manufacture of ostentatious blades of swords, saxes, knives and heads of spears. Such blades and spearheads reveal various forms of pattern-welding and/or strips of phosphoric iron attached to the cutting edges by straight or serrated welds [3-5, etc.]. Phosphoric iron is also a typical feature of Scandinavian variants of sandwiched blades, contrary to the OldRussian variants employing non-phosphoric iron [6].

On the other hand, phosphoric iron can appear in medieval tools and weapons unintentionally, either as a result of the lack of non-phosphoric iron, or due to the use of unsorted heterogeneous or scrap iron. This is well illustrated by the research conducted by Piaskowski [7], who found high average phosphorus contents (from 0.3 up to $0.85 \mathrm{wt} \%$ ) in iron implements coming from several archaeological smelting sites in Poland.

With regard to the current research carried out, it seems that iron with only certain amounts of phosphorus was deliberately involved in the forging of ostentatious blades, whose pattern-welded variants are the most widely known and famous ones in $[5,8,9]$. The ability to distinguish this type of phosphoric iron from those which could appear unintentionally while forging is very important in archaeometallurgic practices; particularly when forged semi-products (such as bars uncovered in smithy workshops) or blades of unusual type are the subject of examination and assessment. Establishing the range of the phosphorus content that is most typical for phosphoric iron used deliberately in the past for aesthetic purposes is therefore, the first goal of this study.

Phosphoric iron can be reliably identified in archaeological weapons and tools using the combination of optical microscopy (OM), due to its highly coarsegrained structure having light appearance when etched with Oberhoffer's reagent or ghost structure, and by hardness measurements, because phosphorus increases the hardness of iron alloys. Nevertheless, archaeometallurgists often need to go beyond simple identification. Today it is possible to measure the $\mathrm{P}$ content in selected areas of metallographic specimens by SEM-EDS/WDS or LA-ICP-MS analysis. But even the most common SEM-EDS analysis is still a money and time consuming method, which is not regularly available for everyday achaeometallographic research. An easier and less expensive method to employ the results of metallographic examination and hardness values and preliminarily estimate the phosphorus content in iron is needed. Hence, the second and the main aim of this study is to establish a hardness-phosphorus content function valid for archaeological iron objects (primarily for blades of knives and swords) and to determine the accuracy of the model. 


\subsection{Detecting the Presence of Phosphoric Iron in Archaeological Objects}

Metallographers can be alerted to the presence of phosphoric iron by the specific appearance of ferritic structure. The so-called ghost structure (Fig. 2a) and coarsegrained ferrite (with grain boundaries often entirely invisible) are the structures typical for phosphoric iron. Ghost structure (GS) can be observed when Oberhoffer's or Klemm's reagents are applied. As Oberhoffer's reagent creates $\mathrm{Cu}$ deposits on low-phosphorus areas, these have a darker appearance when observed under OM [10], Klemm's reagent makes the low-phosphorus areas darker as well and, according to Radzikowska [11], it distinguishes the high and low phosphorus areas, even more precisely than Oberhoffer's etchant. Techniques employing phosphoric iron, such as the pattern-welding technique, can be quickly identified in this manner, if the artifact is sufficiently preserved (see Fig. 2b).

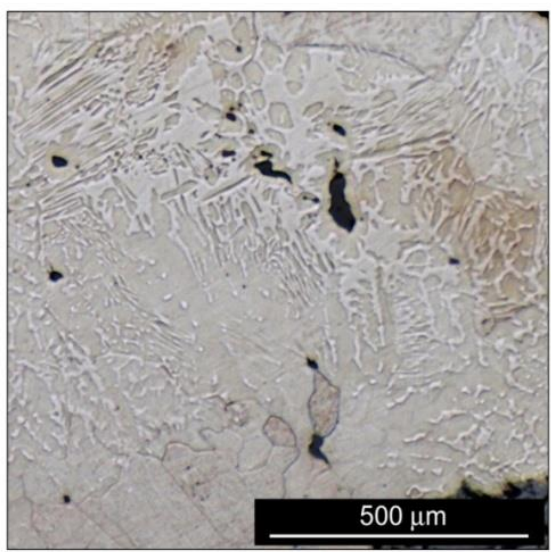

a

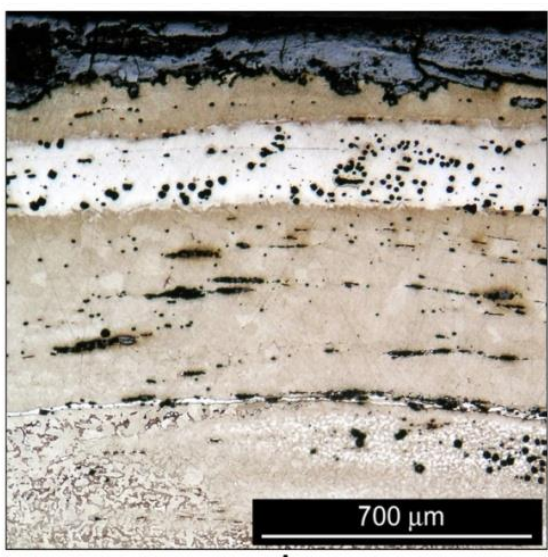

b

Figure 2

Identification of phosphoric iron when etched: a - ghost structure revealed by etching with nital; $\mathrm{b}$ strip (light) of phosphoric iron of a pattern-welded surface panel when etched by Oberhoffer's reagent

The formation of GS is associated with the domain of the coexistence of austenite and ferrite, which appears in the Fe-P binary diagram between c. 0.1-0.7 wt \% and $911-1392^{\circ} \mathrm{C}$ (cf. Fig. 1b). Since phosphorus has lower solubility in austenite than in ferrite, the austenite, which is formed along the ferrite grain boundaries as allotriomorphs and which additionally grows into the ferrite grains in a needleshaped morphology, will contain less phosphorus than the untransformed ferrite [12]. When cooling is sufficiently quick (air cooling), the uneven phosphorus distribution will stay unchanged because of the limited diffusion of phosphorus in ferrite. The ghost structure therefore consists of low- (former austenite) and highphosphorus ferrite, with higher phosphorus content in the grain cores. Literature [1] suggests that structural zones revealing GS can actually contain 0.1-0.7 wt\% P. 
As the ratio between the low- and high-phosphorus ferrite depends on both the overall phosphorus content in the alloy and the applied heat treatment, this ratio cannot be used to estimate the phosphorus content of the iron. Furthermore, if the cooling is sufficiently slow, GS becomes blurred and can even totally disappear.

\section{Theory, Calculations - Strengthening Effects in Phosphoric Iron}

Phosphorus has the strongest solid solution hardening effect on ferrite among substitutional solid-solution strengtheners. Although the difference in the atomic radius of ferrite and phosphorus is higher than $15 \%$ (cf. Hume-Rothery rule), phosphorus still enters the crystal lattice as a substitution solute [13].

In general, the strength of metals is dependent on how easily dislocations in their crystal lattice can be propagated. In substitutional solid solutions, the solute atom replaces the solvent atoms in their lattice positions and dislocations are surrounded by a so called Cottrell-cloud of substitutional solute atoms, so the movement of the dislocation is precluded.

Strength is the mechanical property of metals which can be characterized by the characteristic value of yield strength or proof strength. The increment of proof strength in solid-solution and the specific deformation caused by the solute atom are directly proportional. The specific deformation can be calculated after the equation (1) [14]:

$\varepsilon=\left(\mathrm{r}_{\mathrm{A}}-\mathrm{r}_{\mathrm{B}}\right) / \mathrm{r}_{\mathrm{A}}$

where: $\varepsilon$ - specific deformation (-), $\mathrm{r}_{\mathrm{A}^{-}}$atomic radii of solvent atoms $(\mathrm{pm}), \mathrm{r}_{\mathrm{B}}$ atomic radii of solute atoms $(\mathrm{pm})$.

Empirically measured atomic radii for iron and phosphorus are $140 \mathrm{pm}$ and 100 pm (with an accuracy of about $5 \mathrm{pm}$ ) according to Slater [15].

The yield strength increment can be calculated after the equation (2) [14]:

$\Delta \mathrm{R}_{\mathrm{p} 0.2}=\mathrm{G} \cdot \varepsilon \cdot \mathrm{X}_{\mathrm{c}} / 100$

where: $\Delta \mathrm{R}_{\mathrm{p} 0.2}$ - proof strength increment (MPa), $\mathrm{G}$ - shear modulus (MPa), $\varepsilon$ specific deformation (-), $\mathrm{X}_{\mathrm{c}}$ - atomic percentage of the solute atom (at \%).

The shear modulus of iron is $83000 \mathrm{MPa}$. It can be seen that the increment of proof strength in solid solution and the atomic percentage of the solute atom are directly proportional. Replacing the variables in equation (1) and (2), the calculated proof strength increment is $237 \mathrm{MPa}$ for 1 at $\%$ of phosphorus.

According to Cahoon at al. [16], the following equation can be used to determine the relation between Vickers hardness and yield/proof strength (3a): 
$\mathrm{R}_{\mathrm{p} 0.2}=\left(\mathrm{HV}_{0,2} / 3\right) \cdot(0.1)^{\mathrm{n}}$

where: $\mathrm{R}_{\mathrm{p} 0.2}$ - proof strength $\left(\mathrm{kg} / \mathrm{mm}^{2}\right), \mathrm{HV}$ - Vickers hardness $\left(\mathrm{kg} / \mathrm{mm}^{2}\right)$, $\mathrm{n}$ strain-hardening exponent.

Alternatively, when $\mathrm{n}$ is assumed to be zero, the relation can be expressed in the form of

$\mathrm{HV} \approx 0.3 \cdot \mathrm{R}_{\mathrm{p} 0.2}$

where: HV - Vickers hardness number, $\mathrm{R}_{\mathrm{p} 0.2}$ - proof strength (MPa).

Using the equation ( $3 \mathrm{~b}$ ), the Vickers hardness increment of phosphorus is $71.1 \mathrm{HV}$ for 1 at $\%$. Considering the molar mass of iron $(56 \mathrm{~g} / \mathrm{mol})$ and that of phosphorus (31 $\mathrm{g} / \mathrm{mol}$ ), the theoretical Vickers hardness increment is $127 \mathrm{HV}$ for $1 \mathrm{wt} \%$ of phosphorus, while literature suggests $123 \mathrm{HV}$ or $125 \mathrm{HV}$ hardness increments for $1 \mathrm{wt} \%$ of phosphorus, and a hardness of $60-70 \mathrm{HV}$ for unalloyed ferrite $[3,13]$.

Carbon is the most common element which can appear in phosphoric iron but arsenic can also be detected in elevated concentrations. Such elements as nickel, cobalt or copper are often present in traces but they can easily be revealed because of their increased concentration in welds [17]. These elements, as well as phosphorus, may cause hardness increments.

Phosphoric iron in archaeological objects (like metals in general) can also be strengthened by strain (work) hardening. The flow curve can be calculated using the Ludwig-Hollomon strain hardening equation.

The grain size of phosphoric iron also has an effect on its strength (grain-boundary strengthening). The connection between yield strength and grain size is defined by the Hall-Petch equation.

Heat treatment can also affect the strength of phosphoric iron, although neither Martensitic transformation, nor precipitation (age) hardening appears. The strengthening effect of heat treatment is low, which can be related to the distribution of solved phosphorus (cf. detailed in 1.2). This can be proved by the fact that neither yield strength nor hardness values differ much in case of waterquenched and furnace-cooled states [18].

\section{Methods and Results}

Previously examined metallographic cross sections of four pattern-welded sword blades and six knife blades were chosen for further technical analysis (Fig. 3).

Sword No. 54 is the $10^{\text {th }}$ Century burial find uncovered in the cemetery of Kanín (Bohemia), which belonged to the early medieval stronghold of Libice nad Cidlinou. The sword belongs to type Y, according to Petersen, and represents a 
high quality pattern-welded type sword, albeit the quality of the genuine cutting edges remains unanswered because of the extended corrosion. Sword No. 120 was lifted from an opulent male tomb No. 120 at the burial ground by Libuše-pond near the stronghold of Stará Kouřim (Bohemia). The sword is an unusually short two-edged sword with a high quality pattern-welded blade having unquenched cutting edges of hypereutectoid steel, and unfortunately, bears no significant typological features. According to the enclosed grave articles, the tomb itself can be dated between the first to the second third of the $9^{\text {th }}$ Century. Sword No. 616 comes from Bešeňov (Slovakia). The weapon was lifted from an opulent princely grave and is dated to the $5^{\text {th }}$ Century. The hilt is missing. Sword No. 715 comes from the stronghold of Mikulčice (Moravia), one of the main power centers of the Great Moravian Empire. Lifted from grave No. 715 and dated to the first half of the $9^{\text {th }}$ Century, the sword of type $\mathrm{H}$ according to Petersen represents all the 16 Mikulčice swords as a a pattern-welded weapon of earlier type, made almost entirely of iron. Knives No. 249, 251 and 252 come from Sekanka - Hradišt'ko u Davle (Bohemia) - the $13^{\text {th }}$ Century urban type trading settlement held by the Ostrov Monastery (the Benedictine Monastery of St. John the Baptist at Ostrov). Based on the various evidence of smithy activity and the high concentration of pattern-welded, striped and serrated knives in the craftsman area, it is believed that the production of these opulent knives took place directly at the site. The knives Nos. 251 and 252 were provided with striped blades, knife No. 249 is a basic type of pattern-welded knives. All the knives were products of excellent quality. Knife No. 274 comes from Lahovice (Bohemia) - the burial ground in open terrain, which was used from the mid- $9^{\text {th }}$ to the $11^{\text {th }}$ Century. The knife was lifted from grave No. 274, which can, in general, be dated to the first half of the $10^{\text {th }}$ Century, and which (regarding the enclosed grave goods) does not belong to wealthy burials in the cemetery. Knife No. 423 comes from Mutějovice (Bohemia), where traces of both a settlement from the $10^{\text {th }}$ to $12^{\text {th }}$ Century and two rural smithies (the first of which was in use during the first half, the second in the second half of the $13^{\text {th }}$ Century) were uncovered. The pattern-welded knife No. 423 was a product of superior quality and despite the uncertainties in the dating $\left(12^{\text {th }}\right.$ or $13^{\text {th }}$ Century) it confirms the fact that high quality knives may have appeared even in rural settlements, perhaps as products coming from craft centers. Knife No. 667 was uncovered at Budeč (Bohemia), which was an important stronghold of the $10^{\text {th }}$ and $11^{\text {th }}$ Centuries (founded as early as the turn of the $8^{\text {th }}$ and $9^{\text {th }}$ Centuries) held by the Premyslid family. Knife No. 667 was found at the central part of the stronghold and is interpreted as a $10^{\text {th }}$ to $11^{\text {th }}$ Century striped blade of good quality. 


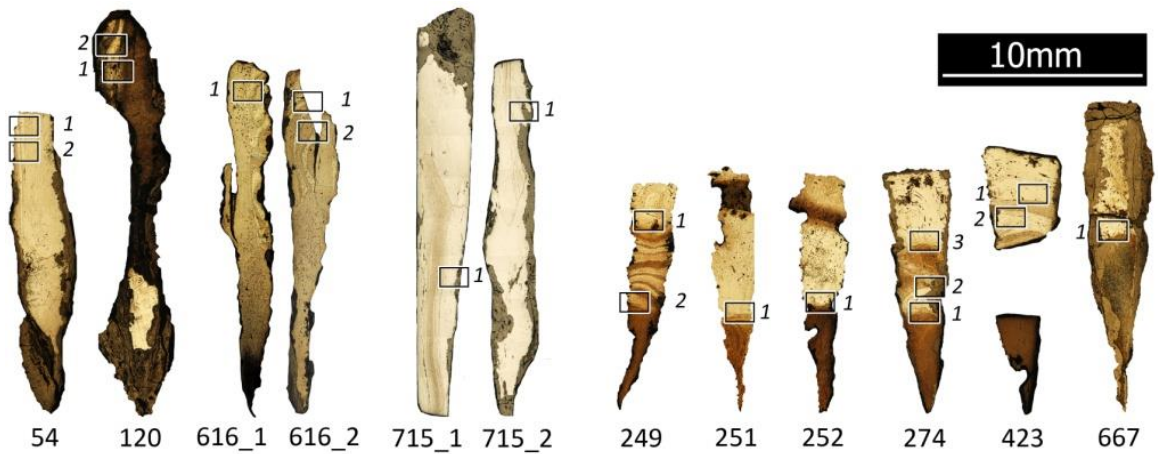

Figure 3

Macro-photographs of investigated metallographic cross sections of medieval sword blades (Nos. 54, 120,616_1, 616_2, 715_1 and 715_2) and knife blades (Nos. 249, 251, 252, 274, 423 and 667). Areas of Vickers hardness measurements with phosphoric iron layers are marked with a rectangle.

The metallographic cross sections of the blades were polished and the Nital2\%etched surface was examined under OM and SEM-EDS to identify the phosphoric iron layers. Fig. 3 shows the macro-photographs of the investigated blade cross sections. The identified phosphoric iron layers on which Vickers hardness measurements were carried out are indicated with rectangles.

The Vickers hardness was measured using a Boehler 1105 micro Vickers hardness tester with a load of $0.2 \mathrm{kgf}$ and a loading time of $10 \mathrm{~s}$. Five hardness measurements were performed on individual phosphoric iron layers (cf. Table 1) of each sample (Fig. 4a). The chemical composition of the area of the indentations imprinted in the surface was then measured using a Philips XL30 Scanning Electron Microscope equipped with an Energy Dispersive Spectrometer (Fig. 4b). The detection limit for phosphorus in phosphoric iron was 0.5 at $\%$ and ca. 0.3 wt $\%$ respectively. This way, a direct relationship between the Vickers hardness and the phosphorus content was found in a total of 90 cases. The results are summarized in Table 1 and Fig. 5.

Table 1

Hardness measurement and EDS analysis results; *anomalous values revealed by linear regression analysis

\begin{tabular}{|c|c|c|c|c|c|c|c|c|c|c|c|}
\hline \multirow{2}{*}{$\begin{array}{l}\text { Object } \\
\text { area } \\
\text { tested }\end{array}$} & \multicolumn{5}{|c|}{ Vickers hardness (HV) } & \multicolumn{5}{|c|}{ Phosphorus content (wt\%) } & \multirow{2}{*}{$\begin{array}{l}\text { Other } \\
\text { element }\end{array}$} \\
\hline & $1^{\text {st }}$ & $2^{\text {nd }}$ & $3^{\text {rd }}$ & $4^{\text {th }}$ & $5^{\text {th }}$ & $1^{\text {st }}$ & $2^{\text {nd }}$ & $3^{\text {rd }}$ & $4^{\text {th }}$ & $5^{\text {th }}$ & \\
\hline 54_1 & $260 *$ & 278 & 270 & 231 & 243 & 0.89 & 1.16 & 1.24 & 1.09 & 1.35 & \\
\hline 54_2 & 226 & 235 & $214^{*}$ & 234 & 244 & 0.99 & 0.91 & 1.27 & 0.93 & 0.85 & \\
\hline $120 \_1$ & 303 & 264 & 275 & 280 & 276 & 1.41 & 1.50 & 1.26 & 1.55 & 1.37 & \\
\hline $120 \_2$ & 274 & 241 & 244 & 257 & 272 & 1.18 & 0.47 & 1.18 & 0.60 & 1.00 & $\mathrm{C}$ \\
\hline 616_1_1 & 299 & 263 & 234 & 221 & 240 & 0.51 & 0.45 & 0.64 & 0.55 & 0.38 & As \\
\hline
\end{tabular}




\begin{tabular}{|c|c|c|c|c|c|c|c|c|c|c|c|}
\hline 616_2_1 & 229 & 234 & 220 & 235 & 230 & 0.60 & 0.70 & 0.16 & 0.64 & 0.60 & As \\
\hline $616 \_2 \_2$ & 220 & 214 & 225 & 231 & 230 & 0.48 & 0.55 & 0.58 & 0.64 & 0.39 & As \\
\hline $715 \_1 \_1$ & 159 & 178 & 156 & 149 & 154 & 0.40 & 0.56 & 0.34 & 0.29 & 0.27 & \\
\hline $715 \_2 \_1$ & 157 & 151 & 150 & 214 & 146 & 0.44 & 0.30 & 0.32 & 0.77 & 0.18 & \\
\hline $249 \_1$ & 263 & 252 & 220 & 254 & 220 & 0.60 & 0.53 & 0.39 & 0.37 & 0.22 & C \\
\hline $251 \_1$ & 185 & 185 & 169 & 174 & 163 & 0.66 & 0.42 & 0.55 & 0.61 & 0.63 & \\
\hline $252 \_1$ & 189 & 188 & 171 & 163 & 148 & 0.69 & 0.61 & 0.60 & 0.61 & 0.43 & \\
\hline $274 \_1$ & 186 & 220 & 199 & 175 & 166 & 0.76 & 0.85 & 0.73 & 0.60 & 0.60 & \\
\hline $274 \_2$ & 188 & 207 & 206 & 199 & 192 & 0.41 & 0.87 & 0.46 & 0.56 & 0.47 & C \\
\hline $274 \_3$ & 160 & 182 & 179 & 187 & 158 & 0.50 & 0.46 & 0.53 & 0.59 & 0.60 & \\
\hline $423 \_1$ & 150 & 141 & 147 & 165 & 159 & 0.46 & 0.26 & 0.43 & 0.46 & 0.63 & \\
\hline $423 \_2$ & 217 & 229 & 232 & 205 & 180 & 0.88 & 0.99 & 0.76 & 0.81 & 0.79 & \\
\hline $667 \_1$ & $165^{*}$ & 205 & 235 & 215 & $225 *$ & 0.79 & 0.81 & 0.89 & 0.65 & 0.45 & \\
\hline
\end{tabular}

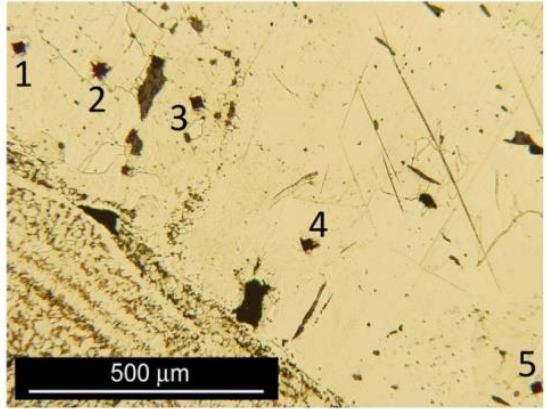

a

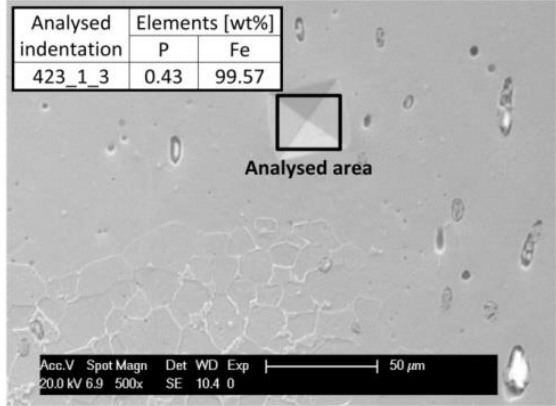

b

Figure 4

Indentations observed under OM in sample 423 area 1 (a) and EDS analysis on the $3^{\text {rd }}$ indentation under SEM (b); (example)

\section{Discussion}

According to our results obtained by means of hardness measurement and EDS analysis (cf. Fig. 5), it seems that phosphoric iron used for the manufacture of ostentatious blades might have contained from 0.4 to $1.4 \mathrm{wt} \%$ of phosphorus on average ( 0.4 to $0.9 \mathrm{wt} \%$ in case of the analyzed knives and 0.4 to $1.4 \mathrm{wt} \%$ in case of the swords). This is in accordance with the values stated in literature $[5,8,9]$. The difference between the minimum and maximum content of $\mathrm{P}$ was $0.35 \mathrm{wt} \%$ on average in a single area tested (in one layer of pattern-welding for instance), but in particular cases it might have been as much as twice higher. In some cases, the phosphoric iron also contained arsenic or carbon besides phosphorus. 


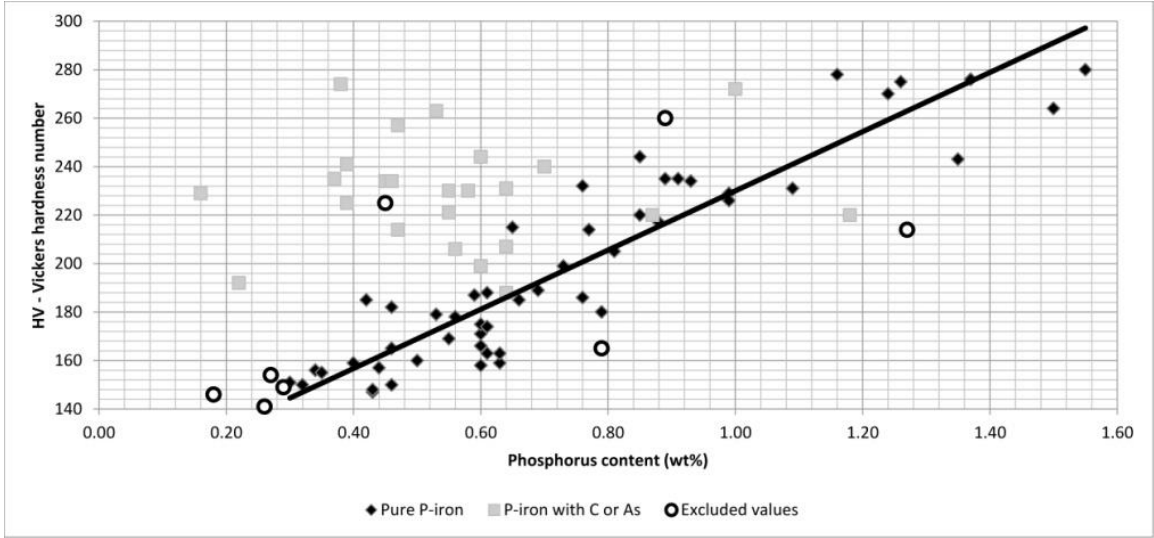

Figure 5

Fitted line plot for the Vickers hardness and the phosphorus content function

In order to determine the relationship between the phosphorus content and Vickers hardness correctly, certain data have to be excluded from further processing. Phosphoric iron enriched in carbon or arsenic has higher hardness than pure phosphoric iron; therefore results related to impure phosphoric iron were excluded (Fig. 5 grey rectangular). Because of the detection limit of the SEM-EDS analysis applied, we excluded the results with less than $0.3 \mathrm{wt} \%$ of phosphorus as well (Fig. 5 white circle). Finally, four anomalous values were also excluded (cf. Table 1, Fig. 5 white circle).

Using the modified data, the following equations have been derived by means of linear regression:

$$
\begin{aligned}
& \mathrm{HV}=(110.1+(119.8 \cdot \mathrm{P})) \pm 15.7 \\
& \mathrm{P}=(-0.919+(0.0083 \cdot \mathrm{HV})) \pm 0.13
\end{aligned}
$$

where:

P - Phosphorus content (wt \%)

HV - Vickers hardness number

According to equation (6), the Vickers hardness increment for 1 wt\% of phosphorus in archaeological iron we have analyzed is $120 \mathrm{HV}$ (thus practically making no difference from the values measured and calculated in modern $\mathrm{Fe}$ alloys) and non-phosphoric iron would theoretically have a Vickers hardness of about $110 \mathrm{HV}$, which means that the phosphoric iron we analyzed was somewhat strengthened additionally, regardless of its phosphorus content.

In our samples, additional strengthening effects in ferrite, besides the solid solution strengthening effect of phosphorus do not significantly affect the deviation of the data, which was most likely caused by measurement uncertainties. 
The strengthening effect of other elements which were in concentration under the detection limits of SEM-EDS should be low. Grain boundary strengthening could also be negligible as a typical coarse-grained microstructure (with a grain size of 100-500 $\mu \mathrm{m}$ ) was observed in all pure-phosphoric iron layers. The blades analyzed underwent some sort of quenching, but this heat treatment does not provide a significant increase in the hardness of phosphoric iron. The strain hardening effect cannot play an important role because significant cold working of the heat-treated blades is unlikely. In conclusion, these effects all together must have caused the hardness increment, which does not depend on the phosphorus content.

The fact that the established relationship is of general application is supported by the analysis of the variance of hardness residuals, which suggests that there are no significant differences among individual objects analyzed in terms of the means of residual hardness values (in other words, all the analyzed blades follow the established HV-P relationship in a similar manner). The standard deviation \pm 16 $\mathrm{HV}$ (the distribution of residuals is reasonably close to a normal distribution) covers both measurement uncertainty and, in general, the insignificant effect of other factors on the hardness of iron alloys.

Within a more complex study of phosphoric iron, performed by Stewart et al. [18], hardness was measured on phosphoric iron containing from 0.1 to $0.38 \mathrm{wt} \%$ P, i.e. in a range which was not researched in this study. The published results show lower hardness values of phosphoric iron, in general, in comparison to our data, which seems to have been caused by the different hardness values of the phosphorus-free iron used.

For an easy estimation of the phosphorus content in archaeological iron objects, conversion Table 2 was developed. When using the table, standard deviation should be considered; for instance, for a hardness of $200 \mathrm{HV}$ the corresponding phosphorus content is $0.75 \pm 0.13 \mathrm{wt} \%$, i.e. there is a $68 \%$ probability that the phosphorus content will be in the range of 0.62 to $0.88 \mathrm{wt} \%$.

Table 2

Vickers hardness values (HV) and corresponding phosphorus content $\mathrm{P}(\mathrm{wt} \%)$ according to equation (5). Standard deviation for phosphorus content is $0.13 \mathrm{wt} \%$

\begin{tabular}{|c|c|c|c|c|c|c|c|}
\hline HV & $\mathbf{P}$ (wt\%) & HV & $\mathbf{P}$ (wt\%) & HV & $\mathbf{P}(\mathbf{w t} \%)$ & HV & $\mathbf{P}(\mathbf{w t} \%)$ \\
\hline 140 & 0.25 & 185 & 0.63 & 230 & 1.00 & 275 & 1.38 \\
\hline 145 & 0.29 & 190 & 0.67 & 235 & 1.04 & 280 & 1.42 \\
\hline 150 & 0.33 & 195 & 0.71 & 240 & 1.08 & 285 & 1.46 \\
\hline 155 & 0.37 & 200 & 0.75 & 245 & 1.13 & 290 & 1.50 \\
\hline 160 & 0.42 & 205 & 0.79 & 250 & 1.17 & 295 & 1.54 \\
\hline 165 & 0.46 & 210 & 0.83 & 255 & 1.21 & 300 & 1.59 \\
\hline 170 & 0.50 & 215 & 0.88 & 260 & 1.25 & 305 & 1.63 \\
\hline 175 & 0.54 & 220 & 0.92 & 265 & 1.29 & 310 & 1.67 \\
\hline 180 & 0.58 & 225 & 0.96 & 270 & 1.33 & 315 & 1.71 \\
\hline
\end{tabular}


The admixture of arsenic in phosphoric iron will lead to the misinterpretation of the phosphorus content when the above method is used. Nevertheless, based on our investigations, it seems that arsenic was not a common admixture of phosphoric iron that we encounter in ostentatious objects we deal with (arsenic was detected only in the object No. 616). It should be noted, however, that in case of arsenic the detection limit and the accuracy of the EDS method are poor. Albeit arsenic makes the determination of phosphorus content by the proposed equation (5) impossible, it is an important admixture of bloomery iron. Arsenic appears only in certain bog-ores and can be removed from iron only with difficulty; therefore its presence in phosphoric iron can serve as a useful guideline in the complex issue of determining provenance [19]. In our case, the sword from Bešeňov is a weapon which differs from the other objects analysed in this study in both dating and provenance.

Unfortunately, there is no way to distinguish pure phosphoric iron from those also containing arsenic by common means of optical metallography [10]. The presence of carbon is suggested by the presence of pearlite (cementite in general) in the structure; therefore, the assessment of such structures should be avoided to estimate the phosphorus content by the proposed method.

\section{Conclusion}

The hardness measurements with detailed chemical SEM-EDS analysis was preformed on archaeologically excavated swords and knives, followed by the statistical treatment of the data obtained. This allowed the following conclusions to be drawn:

1 Phosphoric iron with a wide range of average content $0.4-1.4 \mathrm{wt} \% \mathrm{P}$ (the difference between the minimum and maximum content in a single tested area appears to average $0.35 \mathrm{wt} \%$ ) was used for aesthetic purposes in the manufacture of ostentatious blades

2 When the observed structure of phosphoric iron consists of ferrite without traces of pearlite or ghosting, Vickers hardness (HV) can be used to estimate the phosphorus content $\mathrm{P}$ (wt\%) using the equation:

$\mathrm{P}=(-0.919+(0.0083 \mathrm{HV})) \pm 0.13$

This is particularly but, not exclusively, suitable for heat-treated blades. The accuracy of the estimation is $\pm 0.13 \mathrm{wt} \%$. This equation is not valid when the iron contains arsenic or carbon in addition to the phosphorus. Similarly, when a ghost structure is revealed by etching, the use of the above stated formula may cause misinterpretation.

\section{Acknowledgements}

This work is connected to the scientific program of the " Development of qualityoriented and harmonized $\mathrm{R}+\mathrm{D}+\mathrm{I}$ strategy and functional model at BME" project. This project is supported by the New Hungary Development Plan (Project ID: 
TÁMOP-4.2.1/B-09/1/KMR-2010-0002). The presented research was conducted with the support Czech Science Foundation (project P405/12/2289).

\section{References}

[1] Vega, E., Dillmann, P., Lheritier, M., Fluzin, P., Crew, P., Benoit, P. (2003): Forging of Phosphoric Iron. An Analytical and Experimental Approach. In Archaeometallurgy in Europe, Vol. II, Milan, 337-346

[2] Okamoto, H. (1990): The Fe-P (Iron-Phosphorus) System. Bull. Alloy Phase Diagrams 11(4), 404-412

[3] Tylecote, R. F., Gilmour, B. J. J. (1986): The Metallography of Early Ferrous Edge Tools and Edged Weapons (BAR British Series 155)

[4] Pleiner, R. (2006): Iron in Archaeology. Early European Blacksmiths. Praha: AU AVČR

[5] Hošek, J., Malý, K., Zav'âlov, V. (2007): Železná houba ze Žd'áru nad Sázavou ve světle problematiky fosforového železa ve středověkém nožíŕství. In Archaeologia technica 18. TM Brno. 10-17

[6] Zav‘âlov, V., Rozanova, L. S., Terechova, N. N. (2012): Tradicii $i$ innovacii v proizvodstvennoj kul'ture Severnoj Rusi. Ankil: Moskva

[7] Piaskowski, J. (1989): Phosphorus in Iron Ore and Slag, and in Bloomery Iron, Archaeomaterials 3, 47-59

[8] Kinder, J. (2003): Pattern-welded Viking-Age Sword Blades - What can Modern Metallurgical Investigation Contribute to the Interpretation of their Forging Technology? In: Archaeometallurgy in Europe, Vol. I. 239-248

[9] Thålin, L. (1967): Metallografisk undersökning av ett vendeltida praktsvärd, Fornvännen. 225-240

[10] Stewart, J. W., Charles, J. A., Wallach, E. R. (2000): Iron-Phosphorus Carbon System. Part 2: Metallographic Behaviour of Oberhoffer's Reagent. Material Science Technology 16, 283-290

[11] Radzikowska, J. (1998): The Use of Selective Colour Etching to the Metallographic Identification of Phosphorus Segregation and Technology of Early Implenents Made of Bloomery Iron and Steel. In Metallography'98, 14-19

[12] Piccardo, P., Ienco, M. G., Balasubraman, R., Dillmann, P. (2004): Detecting Non-Uniform Phosphorus Distribution in Ancient Indian Iron by Colour Metallography. Current Science 87, 650-653

[13] Key to Metals - www.keytometals.com (viewed 7 Oct 2013)

[14] Artinger, I. (1982): Anyagszerkezattan, Tankönyvkiadó, Budapest, 19-27 
[15] Slater, J. C. (1964): Atomic Radii in Crystals. Journal of Chemical Physics 41 (10), 3199-3205

[16] Cahoon, J. R., Broughton, W. H., Kutzak, A. R. (1971): The Determination of Yield Strength from Hardness Measurements. Metallurgical Transactions 2(7), 1979-1983

[17] Tylecote, R. F., Thomsen, R. (1973): The Segregation and Surface Enrichment of Arsenic and Phosphorus in Early Iron Artefacts. Archaeometry 15/2, 193-198

[18] Stewart, J. W., Charles, J. A., Wallach, E. R. (2000): Iron-PhosphorusCarbon System. Part 1 - Mechanical Properties of Low Carbon IronPhosphorus Alloys. Material Science Technology 16, 275-282

[19] Piaskowski, J. (1984): Das Vorkommen von Arsen im antiken und frühmittelalterlichen Gegenständen aus Renneisen, Archäologie, Vol. $18,213-126$ 